\title{
INOVAÇÃO E O ASPECTO TERRITORIAL: OBSTÁCULOS À INOVAÇÃO NO BRASIL POR PORTE E GRANDES REGIÕES
}

\section{Ricardo de Sena Abrahão}

Instituto Federal do Triângulo Mineiro (IFTM)

Uberlândia - MG - Brasil

E-mail: ricardosena@iftm.edu.br; ricardo.abrahao@ufu.br

ORCID:https://orcid.org/0000-0002-9122-2332

Recebido em 26/03/2021. Aprovado em 05/07/2021.

DOI: http://dx.doi.org/10.5380/guaju.v7i280232

\section{Resumo}

Este artigo tem como objetivo analisar os diferentes obstáculos à inovação percebidos pelas empresas brasileiras segmentadas por porte e distribuídas conforme as grandes regiões do IBGE, a partir dos dados da Pintec 2014. Por meio de estatística descritiva, o estudo revela aspectos similares para as duas abordagens ao confirmar a preponderância dos fatores de natureza econômica e a falta de profissionais qualificados. Ademais, evidencia-se a maior dimensão dessas barreiras no âmbito das PMEs e uma maior sensibilidade aos obstáculos por parte das empresas da região Norte.

Palavras-chave: PME. Atividade inovativa. Barreira. Desenvolvimento.

\section{Innovation and the territorial aspect: obstacles to innovation in Brazil by size and large regions}

\footnotetext{
Abstract

This article aims to analyze the different obstacles to innovation perceived by Brazilian companies segmented by size and distributed according to the large regions of IBGE, based on data from Pintec 2014. Trough descriptive statistics, the study reveals similar aspects for both approaches by confirming the preponderance of economic factors and the lack of qualified professionals. Moreover, it is evident the greater dimension of these barriers in the scope of SMEs and a greater sensitivity to obstacles on the part of companies in the North region.
}

Keywords: SME. Innovative activity. Barrier. Development. 


\section{Introdução}

Em um ambiente de crescente competitividade e de intensas transformações tecnológicas e sociais, a inovação empresarial se apresenta como alternativa estratégica de diferenciação e aumento da lucratividade para as organizações produtivas (GALIA, MANCINI, MORANDI, 2012; IBGE, 2016), verdadeira força motriz do capitalismo, sendo condição necessária, em que pese não suficiente, para o desenvolvimento (SCHUMPETER, 1943; DALABRIDA et al., 2017).

Considerada a ótica do Estado, o fomento da inovação é um importante instrumento de política pública, tendo em vista o desenvolvimento econômico, em suas múltiplas escalas territoriais (ALBAGLI, 1999; CASSIOLATO, LASTRES, 2002; FEITOSA, 2011; AVELLAR, BOTELHO, 2016). Entretanto, há diversas dificuldades e barreiras que impedem o esforço inovativo das organizações, sejam estas relacionadas ao porte ou à sua localização espacial, considerando a relevância da construção de forças territoriais de competitividade a partir do empoderamento dos atores sociais (BOISIER, 1995; PECQUEUR, 2009).

Tendo em vista os aspectos mencionados, observa-se que as dificuldades e obstáculos apresentados no relatório de inovação do IBGE (Pintec) baseiam-se no Manual de Oslo (OECD, 2005). Entre os fatores avaliados pela Pintec 2014 estão aqueles de natureza econômica, problemas internos à empresa, deficiências técnicas, problemas de informação, problemas com o Sistema Nacional de Inovação (SNI) e problemas de regulação (IBGE, 2016, p. 23). Destaca-se que a edição de $2014^{1}$, penúltima divulgada, retrata os resultados nacionais do triênio 2012-2014 e está em bases comparáveis às dos triênios anteriores e ao seguinte.

O debate da relação entre a inovação e o porte das empresas tem sido objeto de pesquisa tanto no Brasil quanto em outros países pelo mundo (OCDE, 2010). Entre as abordagens estão o estudo dos fatores determinantes da participação inovativa das pequenas e médias empresas (PMEs) e a análise de impacto de programas de apoio às atividades inovativas neste segmento (KLEINKNECHT, 1989; NOOTEBOOM, 1994; AVELLAR, BOTELHO, 2016). A qualificação por porte, também na discussão dos obstáculos, se julga necessária, dada a participação relevante destas firmas na estrutura produtiva e na dinâmica socioeconômica das nações, com influência sobre a geração de emprego e renda. Atualmente,

1 Apesar de já existir uma publicação mais recente, Pintec, 2017 (2015-2017), entendeu-se que, para o propósito deste artigo, os dados da Pintec 2014 (2012-2014) retratam uma conjuntura econômica mais apropriada para a análise dos obstáculos à inovação. Importante salientar o papel central dos fatores de natureza econômica, investimentos de longo prazo e alto risco, no âmbito da inovação empresarial e a profunda crise econômica que se estabelece na economia brasileira nos anos de 2015 e 2016. 
entre as empresas ativas no Brasil, 93\% são microempresas e empresas de pequeno porte, representatividade que pode ser ainda mais significativa, a depender do recorte espacial realizado para as investigações (BRASIL, 2021).

Por sua vez, o estudo da dimensão territorial no processo inovativo se mostra relevante na medida em que fatores como pessoal capacitado e redes de cooperação desenvolvidas constituem fatores impulsionadores da inovação, articulando-se ao processo de desenvolvimento, tanto mais quanto mais articulações forem construídas no território (CASSIOLATO, LASTRES, 2002; DINIZ, SANTOS E CROCCO, 2006; PECQUEUR, 2009). A ausência ou precariedade de tais potencialidades, por si só, constituem-se em verdadeiras barreiras à evolução das atividades inovativas.

Trabalhos anteriores discutem o impacto da inovação sobre o desempenho empresarial (KUMAR, SIDDARTHAN, 1994; GRIFFITH, REDDING, VAN REENEN, 2004; WIGNARAJA, 2012; CARVALHO, AVELLAR, 2017; CALZOLAIO, 2019; YUAN, LI, XIONG, 2021), enquanto isso, principalmente no Brasil, a questão relacionada às barreiras que dificultam ou definitivamente impedem a sua implementação tem sido menos explorada até então. Neste sentido, faz-se necessário avaliar quais as diferenças no apontamento dos obstáculos à inovação das empresas brasileiras por porte e região.

$\mathrm{Na}$ tentativa de contribuir com a literatura nacional acerca dos obstáculos à inovação em um contexto de desenvolvimento territorial, este trabalho tem como objetivo analisar comparativamente o apontamento das barreiras à inovação por empresas brasileiras inovadoras segmentadas por porte (pequena, média e grande) e por grandes regiões geográficas do país (N, NE, S, SE, CO). Para isto, terá como base a Pintec 2014, cujos dados se referem ao período de 2012 a 2014 (IBGE, 2016).

O artigo está composto por cinco seções. Em princípio, esta breve introdução. Em seguida, são apresentadas uma revisão teórica e empírica sobre os obstáculos à inovação, a relação entre inovação e o porte e o papel da região na capacidade de inovar. Mais adiante, revelam-se os aspectos metodológicos da pesquisa, seguidos da apresentação e análise dos resultados propostos pelo trabalho. Por fim, na última seção, são oferecidas as considerações finais. 


\section{Os obstáculos às inovações}

A inovação já tem sido reconhecida na literatura como promotora do crescimento e do desenvolvimento econômico (ALBAGLI, 1999; CASSIOLATO, LASTRES, 2002; FEITOSA, 2011; AVELLAR, BOTELHO, 2016; CALZOLAIO, 2019) e seus determinantes e resultados explorados há algum tempo. Todavia, é importante reiterar que ao se considerar efetivamente o aspecto territorial, em suas múltiplas escalas, trata-se de um requisito necessário, mas não suficiente. Entretanto, tendo em vista a reconhecida relevância do processo inovativo, percebe-se que os fatores que impedem a sua difusão ou simplesmente a dificultam têm sido menos explorados. Este debate poderá auxiliar os gestores privados e públicos a buscarem alternativas de fomento às atividades inovativas em busca do desenvolvimento territorial.

Suzigan e Albuquerque (2008) pesquisaram a relação histórica da interação entre empresas e universidades no Brasil e detectaram um padrão de interações restrito e ainda incapaz de promover o dinamismo desejado para a economia brasileira, tendo como base a ativação da capacidade inovativa no país. Como diagnóstico das causas raízes da limitação do Sistema Nacional de Inovação brasileiro, identificam o começo tardio e problemático da construção das instituições de pesquisa e ensino superior. Apresentam casos de sucesso desta relação universidade-empresa cujas raízes se mostram sólidas e com trajetórias de longa maturação nas áreas das ciências da saúde e agrárias, mineração, engenharia de materiais e metalurgia e engenharia aeronáutica. Acerca da superação dos desafios da difusão da C\&T, ressaltam o papel do tempo, esforço e vontade política.

Por sua vez, Bertoni e Oliveira (2012) investigam os obstáculos à inovação em empresas industriais brasileiras entre 2006 e 2008 a partir dos dados da Pintec, com especial atenção à ausência de capacitações internas. Seus resultados apontam os riscos econômicos excessivos, os custos elevados e a escassez de fontes de financiamento como os entraves mais frequentes às inovações. Adicionalmente, atestam sobre a importância da ausência de capacitação interna como barreira, no entanto, principalmente para as empresas não inovadoras e de pequeno porte, concluem pela preponderância dos problemas de natureza macroeconômica.

Neste mesmo sentido, Kühl e Da Cunha (2013) verificam a percepção de diferentes atores do setor produtivo no que se refere aos obstáculos para a implementação de inovações. Por meio de análises estatísticas, a pesquisa estuda 23 mil empresas agrupadas por segmento e porte segundo a classificação da Pintec. As autoras observam uma maior 
percepção das barreiras à inovação por parte das empresas industriais de pequeno porte e, de maneira geral, um maior impacto percebido pelas questões econômicas. Quanto à decisão de inovar, apontam a falta de informação sobre a tecnologia e a falta de pessoal qualificado como fatores importantes.

Em análise setorial da indústria brasileira, Maia e Silva Filho (2016) coadunam com os resultados da pesquisa anterior ao analisar as principais barreiras à inovação e as diversas percepções neste âmbito. São utilizadas técnicas de estatística multivariada a partir de dados da Pintec (2009-2011) para identificar o comportamento das variáveis nos setores selecionados. Os resultados apontam como sendo os obstáculos mais robustos os custos de inovação, a falta de pessoal qualificado, os riscos econômicos e a escassez do financiamento. Consideraram como variáveis críticas para os diversos setores os riscos econômicos, a rigidez organizacional e os altos custos com a inovação, haja vista que não apresentaram significância estatística na discriminação dos seis clusters estabelecidos, sendo entendidos como fatores mais concorrenciais.

Coad, Pelegrino e Savona (2016) analisam o efeito de diferentes tipos de barreiras à inovação (financeiras, de conhecimento, demanda, estrutura de mercado e regulamentação) no desempenho econômico de empresas do Reino Unido. Os autores empregam regressão quantílica e estimadores de matching em uma análise em painel que se estende de 2002 a 2010 (CIS). Entre as evidências do estudo estão os efeitos negativos das barreiras de custo e disponibilidade de financiamento ao longo de toda a escala de distribuição da produtividade das empresas. Ainda segundo os autores, a falta de pessoal qualificado dificulta sobremaneira as empresas de mais alta produtividade e os efeitos dos obstáculos relacionados à estrutura de mercado não se mostraram significativos.

A relação entre a idade das empresas e sua percepção sobre os obstáculos que impedem ou dificultam a inovação é examinada por Pellegrino (2018). O estudo se baseia em um painel de empresas espanholas entre 2004 e 2011. Como resultado, o autor atesta que diferentes obstáculos são percebidos de maneira distinta por empresas de diferentes idades. Embora seja detectada uma relação negativa entre a idade da empresa e a falta interna e externa de recursos financeiros, um padrão menos claro é identificado em relação aos demais obstáculos. Constata-se, por um lado, que as empresas jovens, em média, parecem ser menos sensíveis à falta de pessoal qualificado quando iniciam um projeto inovador do que quando já estão envolvidas em atividades de inovação. Por outro, as empresas maduras são significativamente afetadas por esse problema. Finalmente, os operadores maduros 
parecem atribuir maior importância aos obstáculos relacionados à estrutura e demanda do mercado do que as empresas com menor grau de experiência.

Na próxima seção, este trabalho explora a literatura que trata da relação entre a inovação e o porte empresarial. A significância deste relacionamento reforça a necessidade de análise dos obstáculos às inovações por essa perspectiva.

\section{A inovação e o porte empresarial}

As relações entre o tamanho das empresas e a sua capacidade inovativa têm impacto direto no dinamismo econômico (SILVA; BOTELHO, 2017). Perceber a contribuição das PMEs (Pequenas e médias empresas) e das GEs (Grandes empresas) à geração e difusão da inovação ou suas dificuldades de implementação se faz necessário para desvelar a complexidade do tema (RIZZONI, 1994).

Em um estudo sobre a relação entre o porte de empresas holandesas e a inovação, medida pelos gastos em Pesquisa e Desenvolvimento (P\&D), Kleinknecht (1989) encontra um número maior de PMEs inovadoras que executam P\&D em pequena escala do que os registros oficiais. Para justificar esta questão, sugere que nas PEs haja dificuldade em formalizar tais gastos. Por sua vez, o autor revela uma tendência das PMEs em serem menos intensivas em P\&D do que as GEs. Ao restringir as observações a empresas inovadoras, não encontra relação sistemática entre o porte e os gastos em $P \& D$. A pesquisa ainda identifica algumas barreiras à inovação para as PMEs, entre elas, déficits de informação sobre políticas de inovação; falta de capital; falta de qualificações administrativas; problemas em encontrar informações técnicas adequadas e empregados qualificados.

Czarnitzki e Hottenrott (2011) apresentam estudo sobre as barreiras financeiras ao investimento em P\&D em contraposição ao investimento de capital. Os dados se referem às pequenas e médias empresas (PMEs) industriais e de serviços alemãs, entre o período de 1992 e 2002, utilizando-se do modelo de regressão Tobit. Entre os seus resultados estão que o investimento em P\&D se diferencia daquele de capital, no que se refere às restrições de financiamento e à importância das fontes internas e externas de financiamento. Mostram uma relação monotônica entre o nível da barreira e o tamanho da empresa para ambos os tipos de investimento. Concluem também que a disponibilidade de fundos internos é mais decisiva para o P\&D e as empresas menores sofrem mais do que as maiores com as restrições externas ao investimento em P\&D. 
Em linha com o debate anterior, o efeito das barreias financeiras naatividade inovativa das PMEs no período pós-crise de 2008 é o foco de Brancati (2015). Por meio do modelo de equações simultâneas, o autor analisa o impacto dos empréstimos bancários na situação financeira das empresas e, indiretamente, estima a probabilidade de inovação condicionada à presença dessa barreira. Os resultados mostram que empresas menores têm menor probabilidade de inovar do que aquelas mais consolidadas quando enfrentam obstáculos financeiros. Por sua vez, têm maior efeito para inovações de produto do que de processo ou organizacionais. Nesse sentido, o empréstimo bancário exerce impactos diferentes de acordo com a tipologia de inovação, sendo mais significativo para a introdução de produtos e processos e mais tênues com melhorias menos radicais. Projetos mais arriscados exigirão melhor relacionamento entre a empresa e o banco.

A relação entre o porte das empresas (pequena e grande) e a atividade inovativa também é o objeto de estudo de Botelho, Maia e Pires (2012). As bases de dados da CIS 6 e da Pintec de 2005 e 2008 são utilizadas para construção do indicador de esforço inovativo das empresas de alguns países selecionados. Os gastos com P\&D, aquisição de conhecimentos externos e de máquinas e equipamentos ganham destaque nesta análise. Os autores explicitam o maior esforço em realizar gastos com atividades inovativas das PEs e seu importante papel no conjunto das atividades de inovação dos países em estudo quando comparadas às GEs.

Sobre os determinantes da cooperação em P\&D, Chun e Mun (2012) investigam pequenas e médias empresas coreanas a partir dos dados da Pesquisa Coreana de 2002 e utilizam o modelo de regressão Probit. Seus resultados sugerem que os spillovers recebidos têm maior efeito no estímulo à cooperação das PMEs com instituições de pesquisa e universidades do que com outros parceiros. Em ambos os tipos de cooperação conclui-se que o conhecimento recebido na cooperação seja maior para as empresas menores. Outra implicação do estudo revela a importância do compartilhamento de riscos com fornecedores e clientes para a cooperação de P\&D das PMEs. Enquanto a busca por conhecimento adicional se trata de determinante essencial para o tipo de cooperação institucional.

Silva e Botelho (2017) analisam a diferença das atividades inovativas entre PMEs do Brasil e de países europeus de acordo com o porte, no período entre 2006 e 2011, com base nos dados da Pintec (Brasil) e da CIS (Europa). A pesquisa considera a taxa de inovação, gastos com P\&D, redes de cooperação e apoio governamental dos países em análise, com especial atenção às características dos Sistemas de Inovação (SNI). O trabalho também 
procura evidenciar os impactos no financiamento à inovação antes e depois da crise de 2008. Entre as conclusões da pesquisa encontram-se o crescimento da taxa de inovação segundo o porte das empresas, apesar da variação significativa entre os países; os gastos em P\&D crescem por porte e, no caso das PEs, há concentração destes em aquisição de máquinas e equipamentos. De outro lado, observa-se maior taxa de cooperação, em geral das GEs com outros agentes, além da dificuldade de financiamento da inovação vivenciada por PEs.

Assim, como se pode notar, o debate acadêmico sobre a influência do tamanho das empresas sobre processo inovativo é intenso e explora o tema em vários aspectos. $\mathrm{A}$ próxima seção traz um apanhado teórico e empírico do papel regional sobre a capacidade inovativa das empresas para, em seguida, iniciar a apresentação e análise dos resultados da presente pesquisa.

\section{Inovação e o aspecto territorial}

Para além da análise das vantagens comparativas, as condições do arranjo produtivo e o desenvolvimento de competências locais ganham especial atenção da academia e governantes há algum tempo. $O$ interesse dos pesquisadores e dos dirigentes cresce na medida em que se constata a influência do território, considerando a forte correlação entre inovação e espaço, e tendo em vista que se trata de uma construção social. Em consonância com Pecqueur (2009), não existe inovação que não esteja ancorada em práticas, tampouco que não esteja situada no espaço.

Compreende-se que o papel da empresa inovadora deve ser mediado pelo ambiente em que ela desenvolve as atividades. O que implica dizer que não há passividade do espaço, mas interação significativa entre os agentes inovadores, unidades empresariais, e todo conjunto sociocultural e econômico que o cerca. O comportamento inovador da empresa interage com o ambiente propício à inovação, que não se circunscreve à oferta de crédito, mas possui abrangência muito mais extensiva, conforme tem sido possível identificar, por um campo cada vez mais sólido de estudos multidisciplinares (MÉNDEZ, 2002).

Nesse contexto, sob a ótica da Economia do Aprendizado (LUNDVALL; JOHNSON, 1994), Asheim (1996) discute sobre o futuro dos distritos industriais. Coloca a capacidade de aprendizado coletivo das PMEs como fator decisivo para o sucesso da transformação desse conjunto de empresas industriais em regiões de aprendizado. Destaca a importância das inovações organizacionais na promoção da cooperação entre as empresas e interessados 
regionais, além da incorporação de sistemas de inovação no nível territorial e regional. Desse modo, com a integração territorial, estes espaços de aprendizagem transcendem do conhecimento tradicional para o conhecimento codificado da economia global.

Cassiolato, Lastres e Szapiro (2000) partem do princípio de que a inovação é um processo desenvolvido socialmente e coletivo. Os autores discutem o papel das políticas de inovação no estímulo às interações entre os agentes econômicos e na difusão do conhecimento local, impulsionando as organizações quando bem articuladas.

A partir da relação entre as instituições e as inovações, Diniz (2001) discute o sucesso econômico local à luz da complexidade proporcionada pela globalização e pelos novos paradigmas tecnológicos e estruturais. Segue daí a centralidade da relação entre a inovação e as institucionalidades para a formulação de políticas adequadas ao desenvolvimento de territórios localizados. Entre o esforço de competir globalmente e, ao mesmo tempo, localmente, emerge a importância da capacitação científica e tecnológica como prérequisito para enfrentamento dessa nova realidade competitiva.

Neste sentido, Cassiolato e Lastres (2002) qualificam a discussão sobre o impacto local a partir de diferentes linhas de estudos: a economia neoclássica tradicional, com olhar direcionado para o valor da gestão e da proximidade geográfica dos atores da cadeia de abastecimento; a economia e ciência regional, com foco no surgimento dos distritos industriais e importância dos ativos não comercializáveis; e a economia neo-schumpeteriana sobre sistemas de inovação com olhar para as políticas e instituições, além do impacto da interação entre os agentes econômicos e capacitação local no fomento do processo inovativo.

Em outra perspectiva, Albagli e Maciel (2004) evidenciam as dimensões socioespaciais e socioinstitucionais na dinâmica inovativa para, em seguida, sugerir caminhos metodológicos para incorporação de tais elementos no estudo dos processos inovativos locais. Os autores enfatizam a produção e a difusão do conhecimento e informações para o aprimoramento da capacidade de inovação interativa. Neste contexto, a avaliação do capital social e da territorialidade aparecem como fatores-chave para a compreensão dos vínculos entre os interessados territoriais, em suas múltiplas escalaridades. A metodologia sugerida permite o entendimento das especificidades de cada região e a possibilidade de aplicação de políticas apropriadas tendo em vista o desenvolvimento territorial.

Em linha com os debates anteriores, Diniz, Santos e Crocco (2006) asseguram o relevante papel da dimensão regional dentro do processo inovativo e a capacidade das redes de cooperação entre empresas e instituições em criar as condições necessárias para 
potencializar a inovação. Destacam o caráter único da trajetória de cada recorte territorial e a necessidade de estratégias públicas específicas para assegurar seu desenvolvimento. Os autores salientam ainda a importância do contínuo aprendizado e capacitação, a fim de efetivar possíveis vantagens comparativas associadas aos recursos naturais.

Adicionalmente, acerca da importância da inovação para o desenvolvimento localizado, Feitosa (2011) aborda a efetividade das políticas que incentivam a interação constante entre os principais atores econômicos no âmbito local, envolvendo empresas, indivíduos e instituições. Reforçam a ideia do conhecimento e da inovação como fatores impulsionadores da competitividade e do desenvolvimento, reconhecendo que a inovação demanda a articulação em rede de atores, políticas públicas e um conjunto de ativos territoriais.

\begin{abstract}
A geração de inovações passa a depender não somente do conjunto de competências da firma individualmente, mas também das capacidades existentes em outras empresas e instituições que integram o sistema econômico. Asinstituições, com seus mecanismos específicos deaprendizado e suas formas de interação, conferem ao local uma participação ativa no processo de criação e difusão de inovações. Dessa forma, a região passa a ser vista como um espaço cognitivo, onde valores compartilhados, confiança e outras formas de ativos intangíveis contribuem para o desenvolvimento de processos de aprendizagem interativos (FEITOSA, 2011, p. 41).
\end{abstract}

Neste sentido, a partir das reflexões de Feitosa (2011), reitera-se que a promoção do desenvolvimento territorial demanda o estabelecimento de um ambiente adequado para os processos de aprendizagem e inovação, uma sintonia entre os agentes econômicos, políticos e comunidade científica, tendo em vista a criação e difusão de políticas específicas, capazes de catalisar o processo inovativo.

Revisada a literatura pertinente, a próxima seção trata dos aspectos metodológicos e abre caminho para a análise e discussão dos resultados do trabalho.

\title{
5 Metodologia
}

Este artigo visa a analisar as diferenças no apontamento dos obstáculos à inovação das empresas brasileiras em duas perspectivas. Primeiro, considerando o porte empresarial e, em seguida, a região geográfica. Olhares distintos, porém complementares.

Para tanto, utiliza-se uma análise descritiva de dados sobre problemas e obstáculos à inovação da Pesquisa de Inovação Tecnológica (Pintec), divulgada trienalmente pelo 
Instituto Brasileiro de Geografia e Estatística (IBGE) com apoio da Financiadora de Estudos e Projetos (Finep) e do Ministério da Ciência, Tecnologia e Inovações (MCTI). As referências metodológicas e conceituais desta pesquisa são o Manual de OSLO (OECD, 2005) e o modelo desenvolvido pela Statistical Office of the European Communities - Eurostat, especialmente a Community Innovation Survey - CIS. Tais documentos têm como premissa a centralidade do desenvolvimento e difusão de novas tecnologias aos países membros, respeitando os diferentes contextos geográficos e territoriais.

O objetivo da Pintec é prover dados e informações para a construção e análise de indicadores setoriais, regionais e nacionais das atividades de inovação das empresas brasileiras ativas no Cadastro Central de Empresas (Cempre) com dez ou mais pessoas ocupadas (IBGE, 2016). As atividades investigadas concentram a amostragem de acordo com a Classificação Nacional de Atividade Econômica (Cnae) nos grupos "potencialmente inovadores". Para a publicação de 2014 utilizou-se o Cnae 2.0, considerando as chamadas indústrias extrativas e de transformação quando se trata da análise por grandes regiões e incorpora os setores de eletricidade e gás e outros serviços quando diz respeito às análises por porte. Há cruzamentos de dados com outras bases como a da Pesquisa Industrial Anual (PIA), a Pesquisa Anual de Serviços (PAS), o que expande as perspectivas de análise.

As principais fontes de dados para a amostra de 2014 da Pintec foram os dados econômicos do IBGE, PIA e PAS, além dos documentos do Ministério do Trabalho e Emprego. Em especial, a Relação Anual de Informações Sociais (Rais) e o Cadastro Geral de Empregados e Desempregados (Caged). Os dados sobre os incentivos fiscais vêm do MCTI, do banco de dados de patentes e contratos do Instituto Nacional da Propriedade Industrial (Inpi), além da PIA-Empresas, da PAS, do Finep e do BNDES (IBGE, 2013; 2016).

Os recortes escolhidos para oartigo dizem respeito aos obstáculos na implementação da inovação para empresas inovadoras brasileiras. Em um primeiro momento, considera-se o porte destas por faixa de pessoal ocupado, em seguida, realiza-se uma análise em nível das macrorregiões brasileiras, independentemente da estratificação anterior (Norte, Nordeste, Sudeste, Sul e Centro-Oeste).

Entre as variáveis do estudo estão a "taxa de inovação" e os tipos de "barreiras enfrentadas durante o processo inovativo" apontadas como de "alta" e "média" relevâncias (Quadro 1), descritas neste trabalho, simplesmente, como barreiras ou obstáculos"relevantes". 
QUADRO 1 - DESCRIÇÃO DAS VARIÁVEIS

\begin{tabular}{|c|c|}
\hline Variável & Descrição \\
\hline Taxa de inovação & $\begin{array}{l}\text { Relação entre o número de empresas que realizaram algum tipo de inovação e o } \\
\text { total de empresas pesquisadas (Pintec) }\end{array}$ \\
\hline $\begin{array}{l}\text { Obstáculos ao } \\
\text { processo inovativo } \\
\text { considerados de alta } \\
\text { e média relevância } \\
\text { ("relevantes") para as } \\
\text { empresas inovadoras }\end{array}$ & $\begin{array}{l}\text { Problemas e obstáculos apontados por empresas que implementaram inovações: } \\
\text { 1. Riscos econômicos excessivos; } \\
\text { 2. Elevados custos da inovação; } \\
\text { 3. Escassez de fontes apropriadas de financiamento; } \\
\text { 4. Rigidez organizacional; } \\
\text { 5. Falta de pessoal qualificado; } \\
\text { 6. Falta de informação sobre tecnologia; } \\
\text { 7. Falta de informação sobre mercados; } \\
\text { 8. Escassas possibilidades de cooperação com outras empresas/instituições; } \\
\text { 9. Dificuldade para se adequar a padrões, normas e regulamentações; } \\
\text { 10. Fraca resposta dos consumidores quanto a novos produtos; } \\
\text { 11. Escassez de serviços técnicos externos adequados; } \\
\text { 12. Centralização da atividade inovativa em outra empresa do grupo. }\end{array}$ \\
\hline
\end{tabular}

FONTE: O autor a partir de PINTEC (2014).

No presente trabalho são consideradas como "empresas que implementaram inovação" aquelas que "introduziram produto (bem ou serviço) e/ou processo novo ou substancialmente aprimorado durante o período 2012-2014" (IBGE, 2016, p. 34).

Já a classificação das empresas por porte está em consonância com a publicação do Gabinete de Estatísticas da União Europeia (EUROSTAT, 2011) e o próprio relatório Pintec 2014, segundo o qual as grandes empresas contêm 250 ou mais pessoas ocupadas; as médias de 50 a 249 e as pequenas de 10 a 49.

\section{Resultados e discussões}

Esta seção apresenta e discute as diferenças nos apontamentos dos obstáculos à inovação realizados por diferentes empresas brasileiras por porte e região, a partir dos dados constantes na Pintec 2014 (IBGE, 2016).

Em linha com evidências empíricas anteriores, a taxa de inovação estratificada pelo porte das empresas apresenta elevação com o aumento do número de trabalhadores empregados (Tabela 1). Botelho, Maia e Pires (2012) confirmam este resultado, mas ressaltam a ausência de linearidade destes quando analisados $n$ à luz de variados setores de atividade e diferentes países. 
Fizeram parte da amostra em 2014 um total de 132.529 empresas potencialmente inovadoras, sendo 47.693 delas consideradas inovadoras de fato. Tal relação representa uma taxa de inovação de $36 \%$. Tomando esse indicador como referência, as pequenas empresas inovadoras representaram 32,9\%; as médias, 47\% e as grandes, 59,5\% (Tabela 1). Os setores constituídos pelas indústrias extrativas e de transformação somaram 117.976 empresas (Tabela 2), enquanto aquelas dos setores de eletricidade e gás e serviços representaram 14.553.

TABELA 1 - TAXA DE INOVAÇÃO DAS EMPRESAS BRASILEIRAS POR PORTE

\begin{tabular}{cccc}
\hline \multirow{2}{*}{ Faixas de pessoal ocupado * } & \multicolumn{3}{c}{$\mathbf{2 0 1 2 - 2 0 1 4}$} \\
\cline { 2 - 4 } & Total Empresas & Inovadoras & Taxa de Inovação (\%) \\
\hline Geral & 132.529 & 47.693 & $\mathbf{3 6 , 0 \%}$ \\
Pequenas (de 10 a 49) & 107.892 & 35.534 & $\mathbf{3 2 , 9 \%}$ \\
Médias (de 50 a 249) & 20.029 & 9.417 & $\mathbf{4 7 , 0 \%}$ \\
Grandes (com 250 ou mais) & 4.607 & 2.742 & $\mathbf{5 9 , 5 \%}$ \\
\hline
\end{tabular}

Fonte: $O$ autor a partir da PINTEC (2014).

NOTA: * Empresas das indústrias extrativa e de transformação e setor de eletricidade/gás e serviços.

O recorte amostral da análise por Grandes Regiões considera apenas as atividades da indústria extrativa e de transformação. Quando se analisa a taxa de inovação nessa perspectiva regional (Tabela 2), as regiões Norte, Sul e Nordeste se destacam com resultados de 43,4\%, 41,1\% e 37,1\%, respectivamente, idênticos aos encontrados por Bezerra (2018). Todavia, é importante observar que a concentração do aparelho produtivo persiste muito significativa nas regiões Sudeste e Sul, o que indica que a tradicional desigualdade regional do capitalismo brasileiro persiste como elemento importante no cenário nacional. Nesse sentido, ainda que haja uma participação relativamente mais elevada das empresas inovadoras na região Norte, pode-se inferir que as ações públicas de fomento à inovação não estiveram devidamente articuladas ao aspecto territorial do desenvolvimento. Isto porque a desconcentração espacial é condição relevante no quadro brasileiro. 
TABELA 2 - TAXA DE INOVAÇÃO DAS EMPRESAS BRASILEIRAS POR GRANDES REGIÕES

\begin{tabular}{cccc}
\hline \multirow{2}{*}{ Grandes Regiões * } & $\mathbf{2 0 1 2 - 2 0 1 4}$ & \\
\cline { 2 - 4 } & Total Empresas & Inovadoras & Taxa de Inovação (\%) \\
\hline Brasil & 117.976 & 42.987 & $\mathbf{3 6 , 4 \%}$ \\
Norte & 3.830 & 1.661 & $\mathbf{4 3 , 4 \%}$ \\
Nordeste & 14.306 & 5.314 & $\mathbf{3 7 , 1 \%}$ \\
Sudeste & 60.423 & 20.354 & $\mathbf{3 3 , 7 \%}$ \\
Sul & 32.501 & 13.370 & $\mathbf{4 1 , 1 \%}$ \\
Centro-Oeste & 6.915 & 2.288 & $\mathbf{3 3 , 1 \%}$ \\
\hline
\end{tabular}

Fonte: Adaptado de Bezerra (2018) a partir da PINTEC (2014).

NOTA: * Empresas das indústrias extrativa e de transformação (recorte amostral).

As amostras utilizadas no levantamento dos problemas e obstáculos de empresas inovadoras brasileiras (PINTEC, 2014) foram compostas pelo perfil de empresas expressos nos Gráficos 1 e 2, por porte e região, respectivamente.

\section{GRÁFICO 1 - AMOSTRA DAS EMPRESAS INOVADORAS POR PORTE}

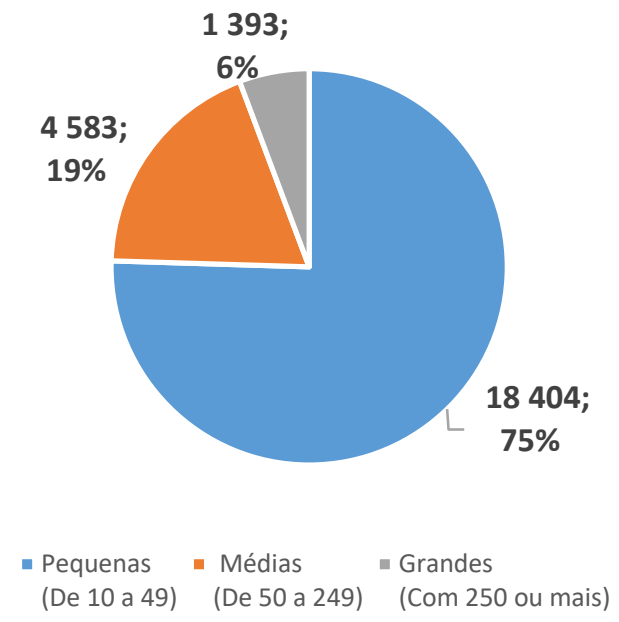

FONTE: O autor; PINTEC (2014).
GRÁFICO 2 - AMOSTRA DAS EMPRESAS INOVADORAS POR GRANDES REGIÕES

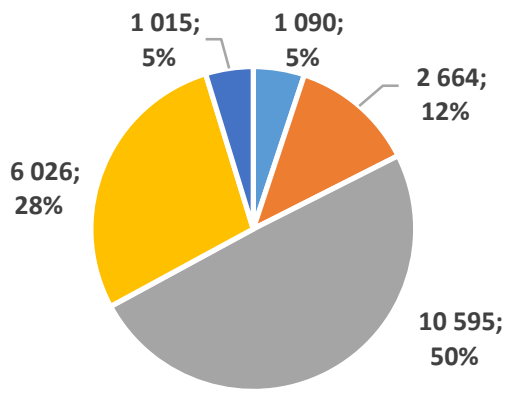

- Norte Nordeste

Sudeste Sul

- Centro-Oeste

FONTE: O autor; PINTEC (2014).

Para os três portes analisados percebe-se nas barreiras à inovação uma similaridade no grau de importância relativo dado a cada obstáculo. Especial atenção aos quatro principais itens mais citados como relevantes pela maior parte dos respondentes. Estes estão relacionados a fatores econômicos e deficiências no quadro de pessoal: "elevados custos da 
inovação", "riscos econômicos excessivos", "escassez de fontes apropriadas de financiamento" e "falta de pessoal qualificado", respectivamente, em destaque no Gráfico 3. Nesse sentido, reitera-se o papel do território, posto que articular a política de inovação envolve complexo arranjo sistêmico, envolvendo atores públicos, privados, instituições de pesquisa e de formação de pessoas. Do ponto de vista organizacional, tais aspectos, observados como obstáculos, estão em seu ambiente externo, dificilmente superados exclusivamente por estratégias de gestão. Questões amplamente discutidas e reveladas em pesquisas anteriores (KLEINKNECHT, 1989; CZARNITZKI, HOTTENROTT, 2011; BERTONI, DE OLIVEIRA, 2012; KUHL, CUNHA, 2013; MAIA, SILVA FILHO, 2016; COAD, PELEGRINO, SAVONA, 2016).

Na outra extremidade do Gráfico 3, o fator associado à "centralização da atividade inovativa em outra empresa do grupo" também mostra convergência entre as empresas de diferentes portes, sendo o problema menos apontado por todos. Apresenta, no entanto, discreta relevância para as grandes, com 10\% de citações. O que, por sua vez, constitui um indicador importante, a ser aprofundado em outras modalidades de investigação, de que a atuação em rede é pouco presente, exceto para as grandes empresas. As redes empresariais e compartilhamento de conhecimento, por sua vez, também representam importante condicionante ao avanço dos processos inovativos e suas interações com desenvolvimento territorial (CASSIOLATO, LASTRES, 2002; DINIZ; SANTOS; CROCCO, 2006; PECQUEUR, 2009).

A "falta de pessoal qualificado" se apresenta como um obstáculo importante para um número maior de empresas pequenas (68\%) do que médias (60\%) e grandes (53\%), (Gráfico 3). De acordo com Pellegrino (2018), as empresas jovens são menos susceptíveis a este problema ao iniciarem seus projetos, mas à medida que se tornam mais maduras são substancialmente impactadas por ele. O que dialoga com o que se observa como requisitos nos arranjos de promoção de ambientes inovadores. 

DOS PELAS EMPRESAS* "INOVADORAS" POR PORTE

$\begin{array}{lllllllllll}0 \% & 10 \% & 20 \% & 30 \% & 40 \% & 50 \% & 60 \% & 70 \% & 80 \% & 90 \% & 100 \%\end{array}$

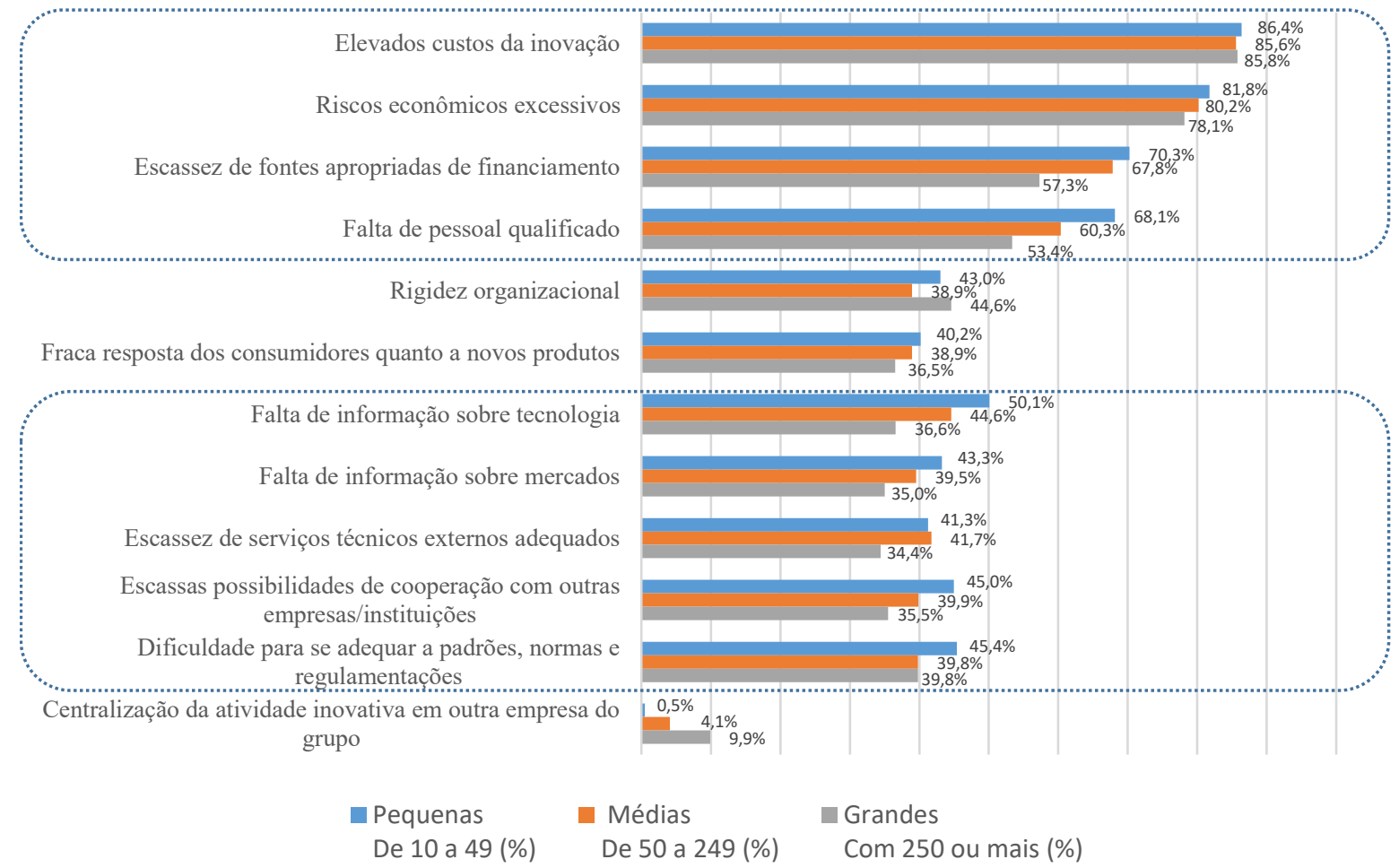

FONTE: O autor a partir da PINTEC (2014).

NOTA: * Empresas das atividades da indústria, do setor de eletricidade e gás e dos serviços selecionados.

$\mathrm{Na}$ lista de obstáculos à inovação, os problemas de informação e regulação, as deficiências técnicas e as dificuldades com o Sistema Nacional de Inovações (SNI) são apontadas, em média, $4 \%$ a mais pelas pequenas em relação às médias e $9 \%$ a mais em relação às grandes empresas. Ou seja, a "falta de informação sobre tecnologia", "falta de informação sobre mercados", "escassez de serviços técnicos externos adequados"e "escassas possibilidades de cooperação com outras empresas/ instituições", são fatores que dificultam sobremaneira as pequenas e médias empresas (PMEs) na condução das atividades inovativas, em destaque na Tabela 3. Em linha com as descobertas de Kleinknecht (1989). Também em consonância com Brancati (2015), na medida em que mostra menor poder de inovação das PMEs frente aos obstáculos financeiros. 
TABELA 3 - OBSTÁCULOS (INFORMAÇÃO, REGULAÇÃO, DEFICIÊNCIAS TÉCNICAS, SNI) ENFRENTADOS PELAS EMPRESAS "INOVADORAS" POR PORTE

\begin{tabular}{l|c|c|c|c|c|c}
\hline \multicolumn{1}{c|}{$\begin{array}{c}\text { Obstáculos à Inovação } \\
\text { “inovadora” }\end{array}$} & \multicolumn{2}{c|}{ Pequenas } & \multicolumn{2}{c|}{ Médias } & \multicolumn{2}{c}{ Grandes } \\
\cline { 2 - 6 } & Quant. & (\%) & Quant. & (\%) & Quant. & (\%) \\
\hline Falta de informação sobre tecnologia & 9.218 & $50 \%$ & 2.043 & $45 \%$ & 510 & $37 \%$ \\
\hline Falta de informação sobre mercados & 7.962 & $43 \%$ & 1.812 & $40 \%$ & 488 & $35 \%$ \\
\hline $\begin{array}{l}\text { Escassez de serviços técnicos externos } \\
\text { adequados }\end{array}$ & 7.593 & $41 \%$ & 1.913 & $42 \%$ & 479 & $34 \%$ \\
\hline $\begin{array}{l}\text { Escassas possibilidades de cooperação } \\
\text { com outras empresas/instituições }\end{array}$ & 8.280 & $45 \%$ & 1.827 & $40 \%$ & 494 & $35 \%$ \\
\hline $\begin{array}{l}\text { Dificuldade para se adequar a padrões, } \\
\text { normas e regulamentações }\end{array}$ & 8.355 & $45 \%$ & 1.824 & $40 \%$ & 555 & $40 \%$ \\
\hline \begin{tabular}{l} 
Média \\
\hline
\end{tabular}
\end{tabular}

FONTE: O autor a partir da PINTEC (2014).

Do ponto de vista das grandes regiões brasileiras, os problemas mais citados em todas elas também se relacionam às questões de natureza econômica e técnicas, "riscos excessivos", "elevados custos", "escassez de financiamento"e "falta de pessoal qualificado"(Gráfico 4). Mesma constatação da análise anterior, por porte. Supõe-se com esta constatação que a composição das empresas do porte guarde a mesma proporção relativa nas regiões estudadas.

Com foco na "falta de pessoal qualificado", outra dificuldade citada regularmente na literatura (SUZIGAN, ALBUQUERQUE, 2008; KÜHL, DA CUNHA, 2013; MAIA, SILVA FILHO, 2016; COAD, PELEGRINO, SAVONA, 2016), constata-se em torno de 64\% das indicações das empresas de todas as regiões como expressiva barreira à inovação. Com exceção da região Nordeste, com índice ainda maior, 73\%, Gráfico 4. Esta variação poderia indicar uma maior dificuldade de contratação de pessoal nesta região específica do Brasil, seja por ausência da força de trabalho especializada ou mesmo pela baixa atratividade da remuneração oferecida nestas localidades.

Os apontamentos dos problemas relevantes pelas empresas da região Norte, quando comparadas às demais regiões, se apresentam percentualmente maiores em fatores relacionados ao mercado, problemas de informação e ao SNI. Em destaque, a "fraca resposta dos consumidores quanto a novos produtos" (68\%), "falta de informação sobre mercados" (66\%), "falta de informação sobre tecnologia" (65\%) e "escassas possibilidades de cooperação" (62\%). A região Centro-Oeste, no que se refere aos fatores de escassez de financiamento, informação sobre tecnologia e cooperação, também expõe indicações 
percentualmente significativas (Gráfico 4). O que, mais uma vez, reitera que as desigualdades regionais brasileiras constituem uma variável relevante a ser considerada na composição deste ecossistema de promoção ao desenvolvimento territorial.

\section{GRÁFICO 4 - APONTAMENTOS DOS PROBLEMAS E OBSTÁCULOS (RELEVANTES) ENFRENTA- DOS PELAS EMPRESAS “INOVADORAS” POR GRANDES REGIÕES}

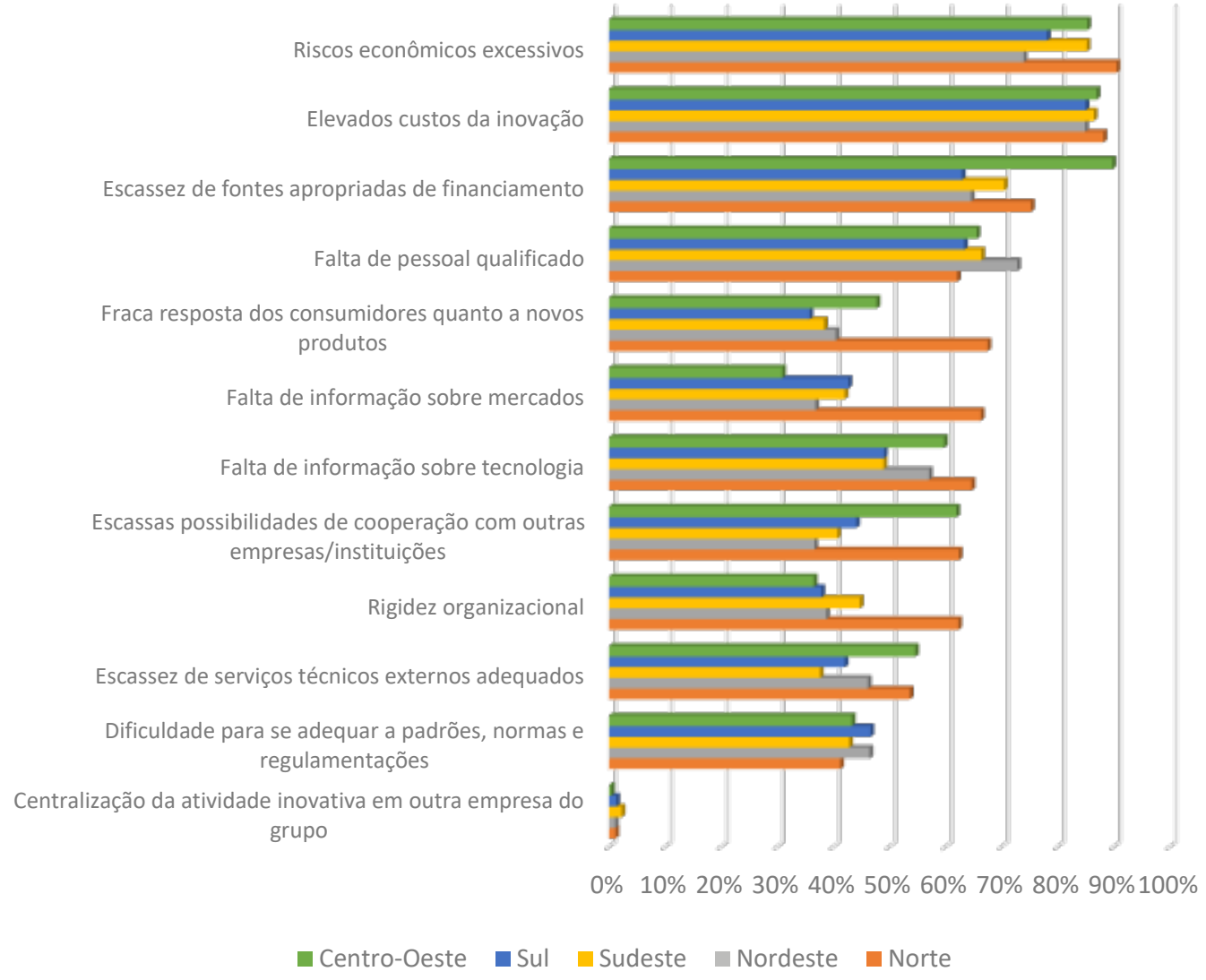

FONTE: O autor a partir de PINTEC (2014).

Adicionalmente, o fato de as empresas, principalmente da região Norte, indicarem percentualmente um maior número de barreiras consideradas relevantes pode estar associado à percepção de dificuldades para se empreender nesta região. Mas também pode estar relacionado às carências regionais e às dificuldades de acesso aos principais mercados consumidores do país, bem como dos principais centros de pesquisa e desenvolvimento tecnológico. O que remete à necessidade de uma maior participação do poder público no fortalecimento dos polos regionais de inovação e de capacitação de pessoal, implicando em um esforço maior para a ruptura da inércia territorial em relação à formação de um ambiente inovador. A seguir, as considerações finais sobre o trabalho. 


\section{Considerações finais}

Diante dos aspectos observados, a avaliação descritiva dos dados da Pesquisa de Inovação 2014 permitiu discutir as diferenças no apontamento dos problemas relacionados à condução da inovação no Brasil, revelando aspectos similares entre as análises por porte e por regiões, aportando indicadores expressivos no que tange às particularidades territoriais no Brasil.

Os fatores de natureza econômica, assim como a falta de profissionais qualificados, ficam evidenciados nas duas perspectivas como obstáculos determinantes para a impulsão das atividades inovativas e, por conseguinte, do próprio dinamismo econômico brasileiro. Neste contexto, tornam-se essenciais ações articuladas do Estado com a sociedade civil no incentivo aos polos tecnológicos e de formação, criando e fortalecendo as economias locais a partir de suas especificidades. Reforçando, portanto, o papel do espaço como elemento dinâmico, bem como o caráter sistêmico requerido de políticas eficazes de apoio e fomento à inovação.

Para além das questões econômicas, que impedem o progresso inovativo de maneira geral, as barreiras à inovação ganham maior dimensão no âmbito das PMEs com fatores associados à falta de informações, dificuldades de obtenção de serviços externos, de adequação a novos padrões e de cooperação com outras instituições. Ressalta-se aqui a importância do papel das universidades e institutos tecnológicos no apoio à inovação e capacitação dos arranjos produtivos locais (APLs) para transformar esse cenário, questões que permeiam a atmosfera do Sistema Nacional de Inovação e enredam o desenvolvimento do país. O que se torna ainda mais importante quando se considera a representatividade das PMEs no aparelho produtivo brasileiro, e, consequentemente, seu poder de promover a difusão dos efeitos positivos do desenvolvimento territorial.

Quanto aos aspectos macrorregionais, o Centro-Oeste e, principalmente, Norte se mostram mais sensíveis à maioria dos obstáculos quando comparados às demais regiões, dadas as suas peculiaridades, reforçando o caráter de concentração regional e a necessidade de enfrentamento do aspecto territorial em suas particularidades e especificidades para casos como o brasileiro. Tal evidência enseja um cenário que pode agravar as desigualdades entre as diferentes regiões do país, haja vista o potencial acelerador do progresso econômico da inovação. 
Frente a estas análises, espera-se que a comparação dos apontamentos das barreiras à inovação para as empresas brasileiras auxilie a discussão nacional e estimule ações privadas e públicas no sentido de mitigá-las. Como sugestão para trabalhos futuros, indica-se uma análise comparativa dos obstáculos à inovação sinalizados pelas empresas brasileiras na Pintec 2014 (2012-2014) e 2017 (2015-2017), considerando as diferentes conjunturas econômicas destes períodos. Outras potencialidades de pesquisa envolvem a articulação dos aspectos relacionados à inovação e aprendizagem às questões socioambientais, seus resultados, barreiras e perspectivas para o desenvolvimento territorial.

\section{Referências}

ALBAGLI, S. Globalização e espacialidade: o novo papel do local. In: CASSIOLATO, J. E.; LASTRES, H. M. M. (Eds). Globalização \& inovação localizada: experiências de sistemas locais no Mercosul. Brasília: IBICT/MCT, p. 181$198,1999$.

ALBAGLI, S.; MACIEL, M. L. Informação e conhecimento na inovação e no desenvolvimento local. Ciência da informação, v. 33, n. 3, 2004.

ASHEIM, B. T. Industrial districts as "learning regions": a condition for prosperity. European Planning Studies, v. 4, n. 4, p. 379-400, 1996.

AVELLAR, A. P. M.; BOTELHO, M. R. A. Efeitos das políticas de inovação nos gastos com atividades inovativas das pequenas empresas brasileiras. Revista Estudos Econômicos, v. 46, n. 3, p. 609-642, 2016.

BERTONI, R. B.; OLIVEIRA, V. C. P. A ausência de capacitações internas às firmas constitui um entrave à inovação no Brasil? In: SEMINÁRIO DE JOVENS PESQUISADORES, 13.; SEMINÁRIO DE ECONOMIA INDUSTRIAL, 13. 2012, Araraquara - SP. Anais... Disponível em: https://www5.pucsp.br/eitt/downloads/21_12_10/xi-ciclo-dedebates/xi-ciclo-rebeca-bertoni-vanessa.pdf. Acesso em: 30 abr. 2021.

BEZERRA, F. D. SILVA. Inovação e desenvolvimento na Amazônia brasileira: uma análise para a Região Norte do Brasil. DRd - Desenvolvimento Regional em debate, v. 8, n. 2, p. 193-208, 2018.

BOISIER, S. Centralización y decentralización territorial en el proceso decisorio del sector público. Santiago de Chile: ILPES/CE-PAL, 1995.

BOTELHO, M. D. R. A.; MAIA, A. F. S.; PIRES, L. A. V. Inovação e porte das empresas: evidências sobre a experiência internacional e brasileira. Revista de Economia, v. 38, n. 1, 2012.

BRANCATI, E. Innovation financing and the role of relationship lending for SMEs. Small Business Economics, v. 44, n. 2, p. 449-473, 2015.

BRASIL. Governo Digital. Painel Mapa de Empresas. Disponível em: https://www.gov.br/governodigital/ptbr/mapa-de-empresas/painel-mapa-de-empresas. Acesso em: 17 jun. 2021.

CALZOLAIO, A. E. Política de inovação da década de 2000: produtividade e inovação. Cadernos do Desenvolvimento, v. 14, n. 25, p. 149-175, 2019.

CARVALHO, L.; AVELLAR, A. P. Innovation and productivity: empirical evidence for Brazilian industrial enterprises. Revista de Administração (FEA-USP), v. 52, p. 134-147, 2017. 
CASSIOLATO, J. E.; LASTRES, H. M. M. O enfoque em sistemas produtivos e inovação locais. In: FISCHER, T. Gestão do desenvolvimento e poderes locais. Salvador: Casa da Qualidade, 2002.

CASSIOLATO, J. E.; LASTRES, H. M. M.; SZAPIRO, M. Arranjos e sistemas produtivos locais e proposições de políticas de desenvolvimento industrial e tecnológico. Nota Técnica 27. Rio de Janeiro, dez. 2000.

CHUN, H.; MUN, S. Determinants of R\&D cooperation in small and medium-sized enterprises. Small Business Economics, v. 39, n. 2, p. 419-436, 2012.

COAD, A.; PELLEGRINO, G.; SAVONA, M. Barriers to innovation and firm productivity. Economics of Innovation and New Technology, v. 25, n. 3, p. 321-334, 2016.

CZARNITZKI, D.; HOTTENROTT, H. R\&D investment and financing constraints of small and medium-sized firms. Small Business Economics, v. 36, n. 1, p. 65-83, 2011.

DALLABRIDA, V. R.; COVAS, M. M. C. M.; COVAS, A. M. A. Inovação, desenvolvimento e espaço urbano: uma relação necessária mas não suficiente. Revista Brasileira de Estudos Urbanos e Regionais (RBEUR), v. 19, n. 2, p. 360-378, 2017.

DINIZ, C. C.; SANTOS, F.; CROCCO, M. Conhecimento, inovação e desenvolvimento regional/local. In. CLÉLIO, C.; $\mathrm{CROCCO}, \mathrm{M}$. (Orgs.). Economia regional e urbana: contribuições teóricas recentes. Belo Horizonte: UFMG, 2006. p. 87-122.

DINIZ, C. C. O papel das inovações e das instituições no desenvolvimento local. In: ENCONTRO NACIONAL DE ECONOMIA, 29., 2001, Salvador.

FEITOSA, C. O. A importância da inovação para o desenvolvimento econômico local. Economia Política do Desenvolvimento, v. 4, n. 12, p. 29-50, 2011.

GALIA, F.; MANCINI, S.; MORANDI, V. Obstacles to innovation and firms innovation profiles: are challenges different for policy makers. In: EURAM CONFERENCE, 12., 2012, Rotterdam, Holland.

GRIFFITH, R.; REDDING, S.; VAN REENEN, J. Mapping the two faces of R\&D: productivity growth in a Panel of OECD Industries. The Review of Economics and Statistics, v. 86, n. 4, p. 883-895, nov. 2004.

INSTITUTO BRASILEIRO DE GEOGRAFIA E ESTATÍSTICA (IBGE). Pesquisa de Inovação - Pintec, 2014. Rio de Janeiro: IBGE, 2016.

KLEINKNECHT, A. Firm size and innovation. Small Business Economics, v. 1, n. 3, p. 215-222, 1989.

KÜHL, M. R.; DA CUNHA, J. C. Obstáculos à implementação de inovações no Brasil: como diferentes empresas percebem sua importância. BBR-Brazilian Business Review, 10(2), 1-25, 2013.

KUMAR, N.; SIDDARTHAN, N. S. Technology, firm size and export behaviour in developing countries: the case of Indian Enterprises. The Journal of Development Studies, v. 31, n. 2, p. 289-309, 1994.

LUNDVALL, B-A; JOHNSON, B. The learning economy. Journal of Industry Studies, v. 1, n. 2, p. 23-42, 1994.

MAIA, M. D. M. A.; SILVA FILHO, J. C. L. Obstáculos a inovação na indústria brasileira: uma análise setorial. Revista Tecnologia e Sociedade, v. 12, n. 26, p. 135-154, 2016.

MÉNDEZ, R. Innovación y desarrollo territorial: algunos debates teóricos recientes. Eure (Santiago), v. 28, n. 84, p. 63-83, 2002.

NOOTEBOOM, B. Innovation and diffusion in small firms: theory and evidence. Small Business Economics, v. 6, n. 5, p. 327-347, 1994. 
ORGANISATION FOR ECONOMIC CO-OPERATION AND DEVELOPMENT (OECD). Oslo Manual: guidelines for collecting and interpreting innovation data. 3. ed. Paris: OECD, 2005.

ORGANIZAÇÃO PARA A COOPERAÇÃO E DESENVOLVIMENTO ECONÔMICO (OCDE). Manual de Oslo: diretrizes para coleta e interpretação de dados sobre inovação. 3. ed. Rio de Janeiro: OCDE, 2010.

PECQUEUR, B. A guinada territorial da economia global. Política \& Sociedade - Revista de Sociologia Política, Florianópolis, v. 8, n. 14, p. 79-105, 2009. Disponível em: https://periodicos.ufsc.br/index.php/politica/article/ view/2175-7984.2009v8n14p79. Acesso em: 14 jun. 2021.

PELLEGRINO, G. Barriers to innovation in young and mature firms. Journal of Evolutionary Economics, v. 28, n. 1, p. 181-206, 2018.

RIZZONI, A. Technology and organisation in small firms: an interpretative framework. Revue d'économie industrielle, v. 67, n. 1, p. 135-155, 1994.

SCHUMPETER, J. A. Capitalism, Socialism and Democracy. London: George Allen \& Unwin, 1943.

SILVA, M. D.; BOTELHO, M. D. R. A. Inovação em pequenas e médias empresas: uma comparação entre Brasil e países europeus selecionados. Blucher, São Paulo, v. 4, n. 2, p. 1497-1517, 2017.

SUZIGAN, W.; ALBUQUERQUE, E. A interação entre universidades e empresas em perspectiva histórica no Brasil. Belo Horizonte: UFMG/Cedeplar, 2008. (Texto para discussão, 329).

WIGNARAJA, G. Innovation, learning, and exporting in China: does R\&D or a technology index matter? Journal of Asian Economics, v. 23, n. 3, p. 224-233, 2012.

YUAN, B.; LI, C.; XIONG, X. Innovation and environmental total factor productivity in China: the moderating roles of economic policy uncertainty and marketization process. Environmental Science and Pollution Research, v. 28, n. 8, p. 9558-9581, 2021. 